\title{
Leaf Anatomy and Stomatal Morphology of Greenhouse Roses Grown at Moderate or High Air Humidity
}

\author{
Sissel Torre, Tove Fjeld, Hans Ragnar Gislerød, and Roar Moe \\ Agricultural University of Norway, Department of Horticulture and Crop Sciences, P.O. Box 5022, \\ N-1432 Ås, Norway
}

ADDITIONAL INDEX WORDS. epicuticular wax, postharvest life, stomatal aperture, Rosa, transpiration rate, water loss

\begin{abstract}
Single node cuttings with one mature leaf were taken from $R$ osa $\times$ hybrida 'Baroness' and rooted in water culture. The plants were subjected to either $90 \%$ (high) or $70 \%$ (moderate) relative humidity (RH) in climate chambers. Single stem roses with intact roots were transferred to $40 \%$ (low) $\mathrm{RH}$ to investigate the stomatal response to water stress. Moderate RH plants showed decreasing leaf conductance from day 1 to day 3 during both light and dark phases, in contrast to high RH roses, which showed almost similar leaf conductances during the 3 days. Leaf samples were studied with a light microscope (LM) and a scanning electron microscope (SEM) to quantify morphological and structural changes. Epidermal imprints showed a significantly higher number of stomata and longer stomata, as well as a wider stomatal apertures on roses grown at high RH. The high RH leaves showed a reduced density of vascular tissue and thinner leaves when compared to moderate RH leaves. Enlarged intercellular air-space (ICA) was found due to a reduced number of spongy and palisade mesophyll cells. No obvious difference in shape, size, undulation or the structure of the epicuticular wax was observed in SEM between high and moderate RH grown leaves. In conclusion, roses subjected to high $\mathrm{RH}$ showed differences in leaf anatomy, stomatal morphology and stomatal function, which may explain the loss of water control of these plants. Stomatal ontogenesis should occur at RH conditions below $85 \%$ to secure roses with a high postharvest quality potential.
\end{abstract}

Postharvest life of cut roses is often limited by water stress. Roses do not undergo a natural senescence process, but end their vase life because of premature wilting of flowers and leaves as well as a bent-neck (Burdett, 1970; Torre and Fjeld, 2001; Zieslin et al., 1978). Transpiration rate and the capacity of the flower tissue to retain water, as well as the water uptake rate and transport determine the water balance of cut flowers in general (Reviewed by Halevy and Mayak, 1981; van Doorn, 1997). Preharvest conditions are known to influence the vase life of roses by affecting their ability to control postharvest water loss. For instance, increasing the daylength in the greenhouse by artificial light, results in an increase in the duration of stomatal opening, higher water loss from the flowering shoot and hence early wilting after cutting (Mortensen and Fjeld, 1998; Slootweg and van Meeteren, 1991). Also humid air ( $>85 \%$ to $90 \% \mathrm{RH}$ ) during growth is a critical environmental factor reducing the postharvest life of cut roses, mainly due to uncontrolled water loss from the cut shoot (Mortensen and Fjeld, 1995; 1998; Mortensen and Gislerød, 1999; Torre and Fjeld, 2001; Torre et al., 2001). Plants cultured in vitro are widely known to display desiccation when transferred to soil and placed in greenhouses. The problem is thought to be due to the high RH of the culture vessels, and plants have shown considerable modifications from what is normally seen in tissue structure and functioning (Brainerd et al., 1981; Sciutti and Morini, 1995; Wardle and Short, 1983). In particular, alterations in leaf anatomy, such as reduced cuticle development and reduced stomatal closure, appear. One objective of this study was to elucidate the extent to which plants grown at high RH undergo similar anatomical and

Received for publication 16 Oct. 2002. Accepted for publication 28 Jan. 2003. The authors thank Vigdis Revhaug for technical assistance. Thanks also to Elisabeth Eng and Trygve Krekling (Department of Chemistry and Biotechnology) and Nina Nagy (Norwegian Forest Research Institute) for assistance during the microscopy work. The work was financially supported by the Norwegian Research Council, project number 107008/111. morphological changes as described for plants regenerated in vitro. In addition, the study was undertaken to evaluate if differences in leaf morphology between high and moderate RH could explain the distinct postharvest behavior of these roses.

\section{Materials and Methods}

Plant material and growing conditions. Rooted stems of Rosa $\times$ hybrida 'Baroness' were grown in growth chambers from single-node segments with a mature leaf in water culture (Torre and Fjeld, 2001). During the rooting period, RH was kept above $90 \%$. After rooting, $\mathrm{RH}$ was adjusted to either high: $90 \% \pm 5 \%$ $(-14.2 \mathrm{MPa})$ or moderate: $70 \% \pm 5 \%(-48.2 \mathrm{MPa}) \mathrm{RH}$. Temperature was kept at $20 \pm 1{ }^{\circ} \mathrm{C}$ and the $\mathrm{CO}_{2}$ at $700 \pm 50 \mu \mathrm{L}^{-1} \cdot \mathrm{L}^{-1}$ during the entire experimental period. All experiments were carried out during the darkest period of the year (January to April and September to December) with a minimal influence of natural sunlight. Artificial light provided by high-pressure-sodium-lamps (SON-T) was supplied $20 \mathrm{~h}$ every $24 \mathrm{~h}$ period with a $4 \mathrm{~h}$ dark period given in between. The average light intensity was $75 \pm$ $10 \mu \mathrm{mol} \cdot \mathrm{m}^{-2} \cdot \mathrm{s}^{-1}$ (measured with a L1-185; LI-COR). Plants were harvested at commercial stage, A (Itzhaki et al., 1990).

Porometer Measurements. Leaf conductance $\left(\mathrm{mmol} \cdot \mathrm{m}^{-2} \cdot \mathrm{s}^{-1}\right)$ was measured on the same plant for three days to study the stomatal response to water stress. Roses with intact roots were transferred from the chambers directly to a test room, placed in 0.5 - $\mathrm{L}$ vases with double destilled water and acclimated for $8 \mathrm{~h}$ before the first measurement with an AP4 porometer (Delta-T Devices LTD, Cambridge, U.K). The temperature in the test room was $20{ }^{\circ} \mathrm{C}, \mathrm{RH}$ was $40 \%(-127.4 \mathrm{MPa})$ and an irradiation level of 14 $\mu \mathrm{mol} \cdot \mathrm{m}^{-2} \cdot \mathrm{s}^{-1}$ was provided by fluorescent tubes for $12 \mathrm{~h}$ per day. Measurements were taken on the abaxial side of the leaves, twice daily, once in the light period and once in the dark period $(3 \mathrm{~h}$ after light off), corresponding to a time when plants had light or 


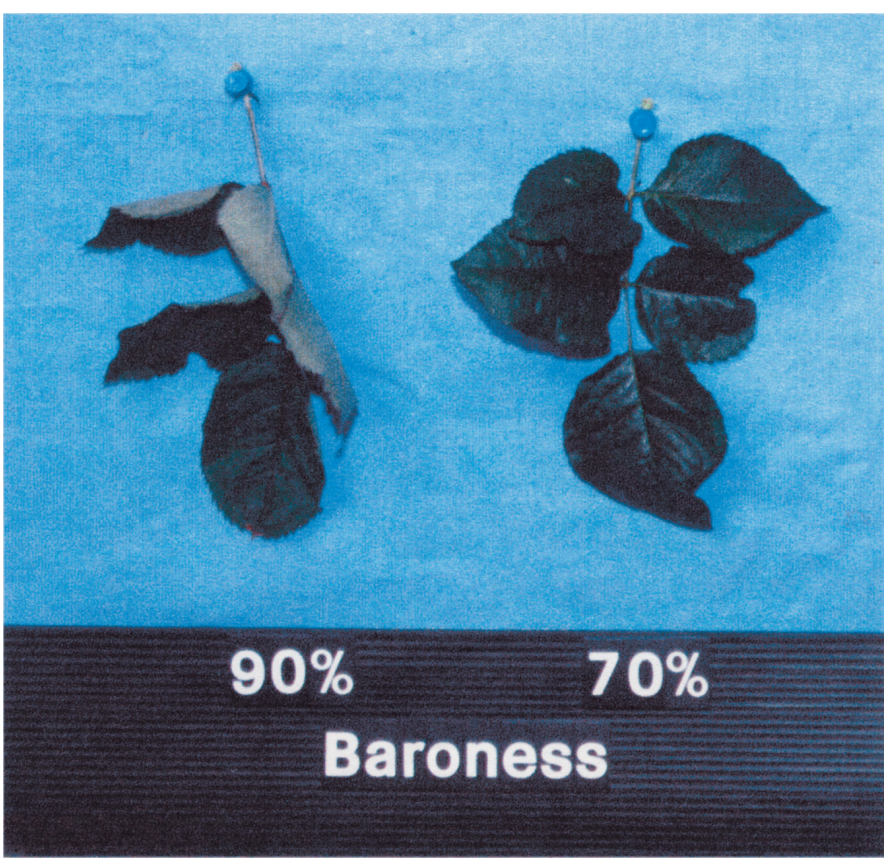

Fig. 1. Leaves from 'Baroness' roses grown at high (90\%) and moderate $(70 \%)$ $\mathrm{RH}, 35$ minutes after detachment. The detached leaves were placed in $20^{\circ} \mathrm{C}$, $\mathrm{RH}$ was $40 \%(-127.4 \mathrm{Mpa})$ and an irradiation level of $14 \mu \mathrm{mol} \cdot \mathrm{m}^{-2 \cdot \mathrm{s}^{-1}}$ was provided by fluorescent tubes.

Table 1. Relative changes in leaf conductance during light and darkness measured on roses with intact roots developed at high $(90 \%)$ and moderate $(70 \%) \mathrm{RH}$ in response to continuous placement in a test room [RH was $40 \%(-127.4 \mathrm{Mpa})$ ] and an irradiation level of $14 \mu \mathrm{mol} \cdot \mathrm{m}^{-2} \cdot \mathrm{s}^{-1}$ was provided by fluorescent tubes $12 \mathrm{~h}$ daily). $(\mathrm{n}=12)$.

\begin{tabular}{lccccc}
\hline & \multicolumn{3}{c}{ Leaf conductance $\left(\mathrm{mmol} \cdot \mathrm{m}^{-2} \cdot \mathrm{s}^{-1}\right)$} \\
\cline { 2 - 3 } \cline { 5 - 6 } Day & \multicolumn{2}{c}{$90 \% \mathrm{RH}$} & & \multicolumn{2}{c}{$70 \% \mathrm{RH}$} \\
\cline { 2 - 3 } \cline { 5 - 6 } & Light & Darkness & & Light & Darkness \\
\hline 1 & 100 & 100 & & 100 & 100 \\
3 & 91 & 96 & & 74 & 58 \\
\hline
\end{tabular}

dark during cultivation. Samples were taken from two independent experiments, each with six plants per treatment.

Stomatal MORPhOlOGY. Roses with intact roots were transferred to a test room (described above) and acclimated for at least one hour prior to sample collection. Epidermal impressions were made on fresh intact upper leaves by applying transparent glue, which covered $\approx 2$ to $3 \mathrm{~cm}^{2}$ of the abaxial surface. After drying ( 2 to $3 \mathrm{~min}$ ) the imprints were removed from the leaf with clear adhesive tape and glued on a microscope slide. All samples were taken interveinal near to the midrib. Stomatal length, aperture and frequency were measured with use of video microscopy and digital image processing (see below). Samples were taken from three independent experiments, each with five plants per $\mathrm{RH}$ treatment.

LIGHT MICROSCOPY AND SEM PROCEDURE. For SEM (JEOL JSM 840 SEM) and LM, fresh fully developed upper leaves were collected and interveinal samples were taken close to the midrib. Sample sections were fixed in $2 \%$ paraformaldehyde and $1.25 \%$ glutaraldehyde in $50 \mathrm{mmol} \cdot \mathrm{L}^{-1} \mathrm{~L}$-piperazine-N-N'-bis(2-ethane sulfonic) acid buffer ( $\mathrm{pH} 7.2)$ for $24 \mathrm{~h}$ at room temperature.
Fixed tissue was rinsed with the same buffer, and dehydrated in an ethanol series (70\% to $80 \%$ to $90 \%$ to $96 \%$ to $4 \times 100 \%$ ). For SEM, fixed and dehydrated samples were critical point dried with $\mathrm{CO}_{2}$, mounted on aluminum stubs and sputter coated with palladium-platinum. Samples for LM were infiltrated with L.R. White acrylic resin (TAAB Laboratories, U.K), and polymerized at $60{ }^{\circ} \mathrm{C}$ for $24 \mathrm{~h}$. For the LM study, semithin (1 to $2 \mu \mathrm{m}$ ) sections were cut with a glass knife. The sections were dried on silanated slides, stained with Stevenel's blue (del Cerro et al., 1980), mounted with immersion oil, and imaged and analysed in a Leitz Aristoplan light microscope with use of video microscopy and digital image processing (Image Pro Plus, ver. 3.0). For carbohydrate staining, the periodic acid/Schiffs (PAS) method was used. LM sections were oxidized with periodic acid (1\%) for $30 \mathrm{~min}$, then washed with distilled water, and treated with Schiffs reagent (Sigma Chemical Co.) for $2 \mathrm{~h}$ in darkness. Control slides were incubated in distilled water prior to treatment with Schiffs reagent. After several washes, the sections were dried, mounted, and imaged as above. PAS is selective for carbohydrate residues with vicinal-hydroxyl groups, which in the first step is oxidized to aldehyde groups by periodic acid, and then reacts with Schiffs reagent to give a pink-colored complex (Hotchiss, 1948; McManus, 1948). Samples were taken from two independent experiments, each with 5 plants per RH treatment for both SEM and LM analysis.
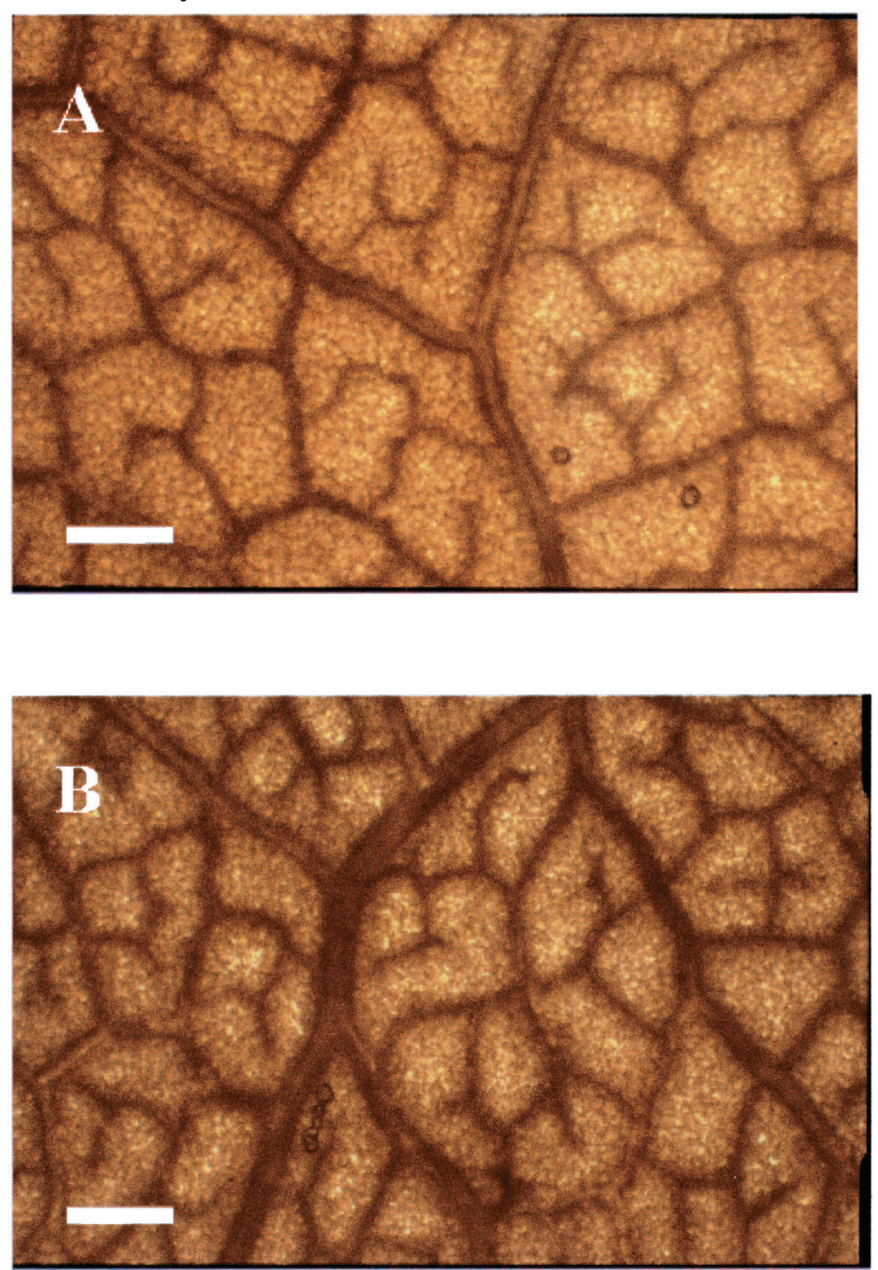

Fig. 2. Detached upper leaves from 'Baroness' roses grown at (A) high (90\%) and $(\mathbf{B})$ moderate $(70 \%) \mathrm{RH}$, bleached by placement in ethanol $(100 \%)$ for $24 \mathrm{~h}$. Photographs were taken interveinal close to the mid-rib. Scale bars = $0.5 \mathrm{~mm}$. 
Table 2. Leaf morphology characteristics ${ }^{\mathrm{z}}$ of roses grown at high (90\%) and moderate $(70 \%) \mathrm{RH}$.

\begin{tabular}{lcc}
\hline Leaf morphology & $90 \%$ RH & $70 \% \mathrm{RH}$ \\
\hline Leaf thickness $(\mu \mathrm{m})$ & $139.8 \mathrm{a}^{\mathrm{y}}$ & $167.4 \mathrm{~b}$ \\
Thickness of upper epidermis cells $(\mu \mathrm{m})$ & $16.3 \mathrm{a}$ & $18.9 \mathrm{~b}$ \\
Thickness of lower epidermis cells $(\mu \mathrm{m})$ & $13.5 \mathrm{a}$ & $17.3 \mathrm{~b}$ \\
ICA $(\%)$ & $49.1 \mathrm{a}$ & $39.9 \mathrm{~b}$ \\
Spongy mesophyll cell number $/ \mathrm{mm}^{-2}$ & $628 \mathrm{a}$ & $797 \mathrm{~b}$ \\
Palisade mesophyll cell number $/ \mathrm{mm}^{-2}$ & $911 \mathrm{a}$ & $1003 \mathrm{~b}$
\end{tabular}

${ }^{2}$ Statistical difference was calculated by a two-way ANOVA with two independent replications of the experiment. Data was sampled from five plants in each replication.

yDifferent letters in the same line indicate significant difference $(P \leq 0.05)$.

Table 3. Stomatal characteristics ${ }^{2}$ of roses grown at high (90\%) and moderate $(70 \%) \mathrm{RH}$.

\begin{tabular}{lcr}
\hline Stomatal characteristics & $90 \% \mathrm{RH}$ & $70 \% \mathrm{RH}$ \\
\hline Stomatal number $/ \mathrm{mm}^{-2}$ & $52.0 \mathrm{ay}$ & $39.0 \mathrm{~b}$ \\
Stomatal aperture $(\mu \mathrm{m})$ & $12.6 \mathrm{a}$ & $9.0 \mathrm{~b}$ \\
Stomatal length $(\mu \mathrm{m})$ & $36.0 \mathrm{a}$ & $32.4 \mathrm{~b}$
\end{tabular}

${ }^{2}$ Statistical difference was calculated by a two-way ANOVA with three independent replications of the experiment. Data was sampled from five plants in each replication.

${ }^{y}$ Different letters in the same line indicate significant difference $(P \leq$ $0.05)$.

\section{Results}

LEAF CHARACTERISTICS. Leaves of high and moderate RH roses showed similar general appearance during development and at the stage of harvest. However, the transpiration rate was much higher in high $\mathrm{RH}$ roses than in moderate $\mathrm{RH}$ roses. This was clearly demonstrated by detached leaves. Fully developed leaves from roses grown at high $\mathrm{RH}$ showed wilting signs $30 \mathrm{~min}$ after detachment (Fig. 1). The conductivity of high RH roses with intact roots did not show any tendency to decrease during time: at day 3 the leaves still showed the same relative conductance as the first day of measurement, both in light and darkness. In contrast, the stomata of moderate $\mathrm{RH}$ roses responded when placed in dry air with decrease in relative leaf conductance over time being observed in light and darkness (Table 1). The leaves of roses have reticulately branched veins, which are pinnate (with one central vein, the midrib, and smaller branching veins). For studying the vascular bundle pattern between two branches, it was clear that the density of the vasculature was higher in roses grown at moderate $\mathrm{RH}$ than high RH (Fig. 2). In addition, significantly thinner leaves were found in high $\mathrm{RH}$ plants (Table 2).

Stomatal AND EPIDERMal ChaRACTERISTICS. Stomatal morphology confined to the abaxial surface of leaves is presented in Table 3. Asignificantly higher number of stomata and longer stomata were found in plants grown at high RH compared to plants grown at moderate RH. The variability in stomatal size was higher in the high RH plants (data not shown), and several of the stomata were remarkably larger than those of moderate RH plants. Figure 3A shows a giant stomata from high RH leaves and a normal one from moderate RH leaves (Fig. 3B). Stomatal aperture was found to be $\approx 25 \%$ wider on the imprints taken from high RH plants compared to the moderate RH plants. The epidermis and stomata of high and moderate $\mathrm{RH}$ leaves were studied with the SEM (Fig. 3C and 3D). The lower epidermal surface on the high and moderate RH leaves looked somewhat similar. No obvious variation in shape, size or undulation was observed in the SEM between high and moderate RH. Furthermore, no apparent differences in the structure of the epicuticular wax were observed between the two treatments. No hydathodes were observed on either high or moderate RH leaves.

LEAF MORPHOLOGY. Cross-sections of leaves showed that elevated RH induced structural modifications (Fig. 4, Table 2). Significantly more intercellular air spaces and a reduced number of both palisade and spongy mesophyll parenchyma cells were measured on the high RH leaves. The thickness of epidermal cells on both sides was lower in high than in moderate RH leaves (Table 2). Moderate RH leaves showed a stronger tendency for developing two layers of palisade parenchyma. The PAS reagent stained cell walls and starch grains of the tissue. In general, the moderate RH leaves tended to show more starch grains and a stronger coloration compared to the high RH tissue (Fig. 4).

\section{Discussion}

Stomatal behavior can be influenced by environmental factors in a direct or indirect manner. When a plant is exposed to water stress, tissue water potential will normally decrease. This condition is transmitted to the guard cells via hydroactive and/or hydropassive mechanisms and stomata close (Willmer and Fricker, 1996). Despite the much higher water loss from high RH roses they continued to lose just as much water during the three days in light and darkness. This means that the stomata of the high

Fig. 3. Epidermal cells of a 'Baroness' rose leaf. Abaxial epidermis peel of upper leaves grown in (A) high (90\%) and (B) moderate $(70 \%)$ RH. Note that the guard cells of the high RH leaves contain less starch grains. Scale bars $=8 \mu \mathrm{m}$ Scanning electron micrographs of the abaxial epidermal surface of leaves grown in (C) high and (D) moderate RH showing wax cover and numerous stomata.
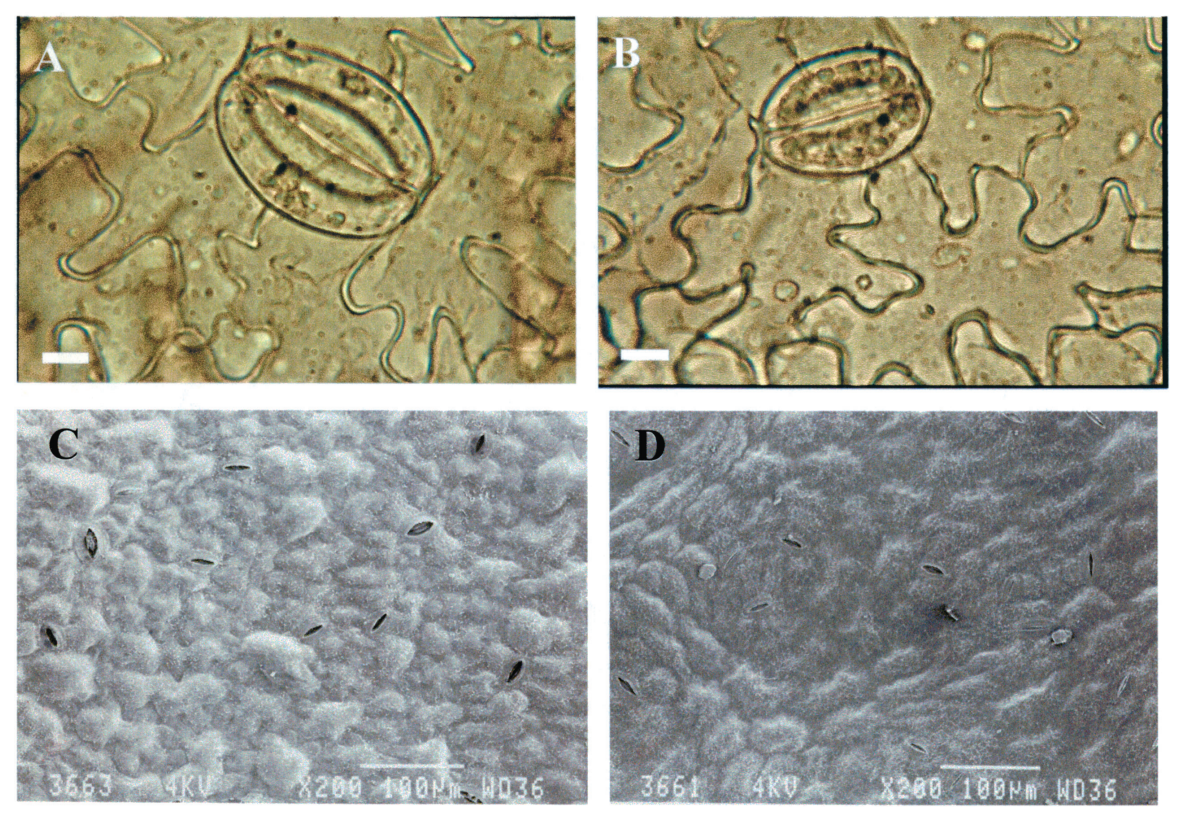

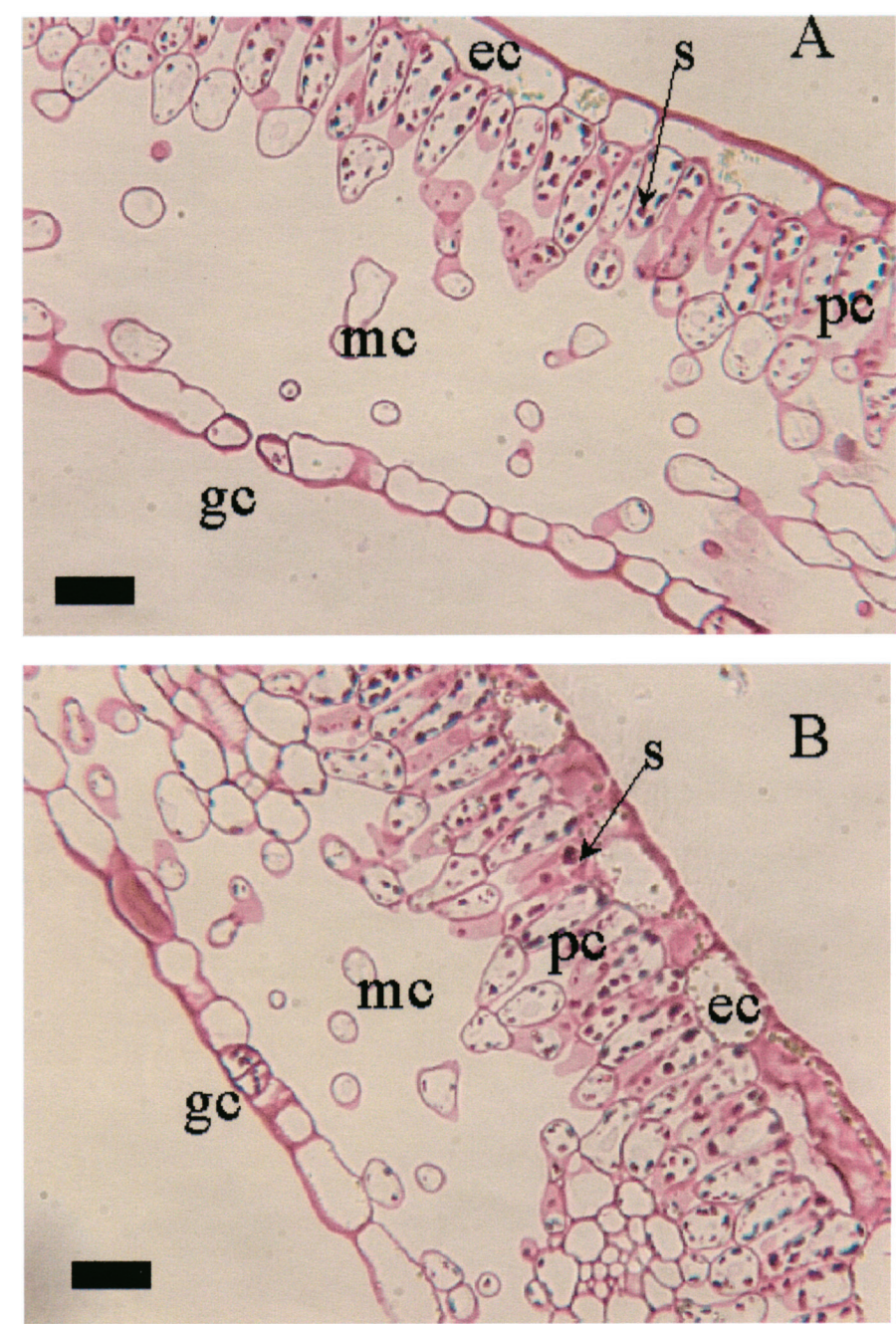

Fig. 4. Light photomicrograph cross-sections of 'Baroness' rose leaves grown at (A) high (90\%) and (B) moderate (70\%) RH, stained with carbohydrate staining (PAS). Note the strong coloration of the moderate RH upper epidermis. ec $=$ epidermal cell, $\mathrm{gc}=$ guard cell, $\mathrm{mc}=$ mesophyll cell, $\mathrm{pc}=$ palisade cell, $\mathrm{s}=$ starch. Scale bars $=12.5 \mu \mathrm{m}$.

$\mathrm{RH}$ roses are insensitive to water stress and that the situation is somehow irreversible. In contrast, moderate $\mathrm{RH}$ roses responded to dehydration by stomatal closure, indicating that they are more competent to adapt when transferred to an interior climate than high $\mathrm{RH}$ roses.

The microscopy analysis showed that RH affected the morphological development of the leaf tissue during growth Alterations in stomatal morphology and enlarged ICA due to reduced palisade and spongy mesophyll parenchyma cells were observed in leaves of plants grown at high RH. Microscopic examinations of leaves produced in vitro have shown, in many cases, that they either possess a very thin palisade tissue or lack it all together. Most of the unorganized mesophyll consists of spongy parenchyma that is rich in ICA(Paques and Boxus, 1987). Alterations in stomatal morphology in micropropagated plants have been reported in several species, including Malus (Blanke and Belcher, 1989), Delphinium (Santamaria et al., 1993), Prunus (Sciutti and Morini, 1995) and in Rosa (Cappellades et al., 1990; Ghashghaie et al., 1992). Exceptionally large stomata, many of which have developed abnormally with pores 'locked' open are commonly found in in vitro plants (Willmer and Fricker, 1996).
In the present study, occasionally large stomata could be observed on the high $\mathrm{RH}$ leaves.

The fact that stomata are large does not explain why high RH leaves dehydrate rapidly after detachment. In some studies, discontinuity in the epidermis and epidermal pores in association with stomata have been found in in vitro plants, and suggested these are the main cause of desiccation in vivo as was the case for Gypsophila (Gribble et al., 1996). Discontinuity was not observed on the epidermis of the high RH rose leaves when studied with the SEM in the present study. Neither did we observe any obvious differences in shape, size nor undulations of the epidermal layer as described previously for in vitro rose plants (Cappellades et al., 1990). Recent suggestions have indicated reduced cuticle development and lack of cuticular waxes to be one of the major causes for desiccation of in vitro plants (Fabbri et al., 1986; Sutter and Langhans, 1982). However, no obvious difference in epicuticular wax was observed with the SEM between high and moderate RH plants. Finally, it may be concluded that the excessive water loss of the high RH plants cannot be explained by a poorly developed epidermis, either on the adaxial or abaxial side. The former was previously confirmed by porometer measurements (Torre and Fjeld, 2001).

A lower density of vascular tissue was observed on high $\mathrm{RH}$ leaves. The differentiation and development of the vascular bundles are known to be affected when plants are grown under very humid conditions (Smith et al., 1986). Enlarged ICA and guard cells protruding above the epidermal surface are structural adaptations that may assist in increasing the water loss from high RH plants. However, the main reason for the high water loss of high RH plants seems to be a higher number of stomata with a reduced function. There is currently little information on the molecular control of stomatal initiation and spacing patterns. It is however well known that the stomatal index depends on the environment in which the leaves develop (Schoch et al., 1980). Lack of stomatal closure has been observed in several micropropagated plants, including roses (Cappelades et al., 1990; Sallanon et al., 1993; Short et al., 1981). In roses, the lack of closure was attributed to high levels of $\mathrm{K}$, which the guard cells accumulated from the salt rich culture medium (Short et al., 1981). A lower $\mathrm{Ca}$ level is currently found in leaves of high RH roses. However, by manipulating the $\mathrm{K} / \mathrm{Ca}$ ratio, only slight or inconspicuous differences in the day/night transpiration rate ratio were observed in rose leaves (Torre et al., 2001). Hence, it is most unlikely that nutrient status of the high RH plants can explain the reduced stomatal response to water stress.

Several authors have suggested that failure of stomatal closing lies mainly in the guard cell wall (Ziv et al., 1987) and that stomata from leaves raised in vitro cannot be fully repaired or become functional (Sallanon et al., 1993). The fact that the high RH roses did not respond fully to darkness (Torre and Fjeld, 2001; Torre et al., 2001) or to water stress over time, indicated a similar structural and/or physiological malfunctioning of the stomata. However, more research is needed to define the limitation on closing more in detail.

In conclusion, the excessive water loss from the high RH leaves is due to a higher number of stomata with a wider aperture that are unable to close fully. High RH tends to affect the anatomical and morphological characteristics of the leaves in a similar, however in a less apparent, way as reported in micropropagated plants. Earlier work has shown that RH during growth is decisive for the postharvest life. Cut roses grown at high $\mathrm{RH}(85 \%$ to $90 \%)$ show premature wilting of flowers and leaves and bent necks. 
The structural and functional characteristics of leaves developed at high RH described in the present study may explain why these roses show such a poor postharvest longevity. Thus, stomatal ontogenesis should occur at RH conditions below $85 \%$ to secure roses with a high postharvest quality potential.

\section{Literature Cited}

Brainerd, K.E., L.H. Fuchigami, S. Kwiatowski, and C.S. Clark. 1981. Leaf anatomy and water stress of aseptically cultured Pixy plum grown under different environments. HortScience 16:173-175.

Blanke, M.B. and A.R. Belcher. 1989. Stomata of apple leaves cultured in vitro. Plant Cell Tissue Organ Cult. 19:85-89.

Burdett, A.N. 1970. The cause of bent neck in cut roses. J. Amer. Soc. Hort. Sci. 95:427-431.

Capellades, M., R. Fontarnau, C. Carulla, and P. Debergh. 1990. Environment influences anatomy of stomata and epidermal cells in tissuecultured Rosa multiflora. J. Amer. Soc. Hort. Sci. 115:141-145.

del Cerro, M., J. Cogen, and C. Del Cerro. 1980. Stevenel's blue, an excellent stain for optical microscopical study of plastic embedded tissues. Microscopica Acta 83:117-121.

Fabbri, A., E. Sutter, and S.K. Dunston. 1986. Anatomical changes in persistent leaves of tissue cultured strawberry plants after removal from culture. Scientia Hort. 28:331-337.

Ghashghaie, J., F. Brenckmann, and B. Saugier. 1992. Water relations and growth of rose plants cultured in vitro under various relative humidities. Plant Cell Tissue Organ Culture 30:51-57.

Gribble, K., V. Sarafis, J. Nailon, P. Holford, and P. Uwins. 1996. Environmental scanning electron microscopy of the surface of normal and vitrified leaves of Gypsophila paniculata (Babies Breath) cultured in vitro. Plant Cell Rpt. 15:771-776

Halevy, A.H. and S. Mayak. 1981. Senescence and postharvest physiology of cut flowers - Part 2. Hort. Rev. 3:59-143.

Hotchkiss, R.D. 1948. A microchemical reaction resulting in the staining of polysaccharide structures in fixed tissue preparations. Arch Biochem. 16:131

Itzhaki, H., A. Borochov, and S. Mayak. 1990. Age-related changes in petal membranes from attached and detached rose flowers. Plant Physiol. 94:1233-1236.

McManus, J.F.A. 1948. Histological and histochemical uses of periodic acid. Stain Technol. 23:99-108.

Mortensen, L.M. and T. Fjeld. 1995. High air humidity reduces the keeping quality of cut roses. Acta Hort. 405:148-155.

Mortensen, L.M. and T. Fjeld. 1998. Effects of air humidity, lighting period and lamp type on growth and vase life of roses. Scientia Hort. 73:229-237.

Mortensen, L.M. and H.R.Gislerød. 1999. Influence of air humidity and lighting period on growth, vase life and water relations of 14 rose cultivars. Scientia Hort. 74:1-10.

Paques, M. and P. Boxus. 1987. Vitrification : A phenomenon related to tissue water content. Acta Hort. 212:245-252.

Sallanon, H., D. Laffray, and A. Coudret. 1993. Ultrastructure and functioning of guard cells of in vitro cultured rose plants. Plant Physiol. Biochem. 29:333-339.

Santamaria, J.M., W.J. Davies, and C.J. Atkinson. 1993. Stomata of micropropogated Delphinium plants respond to $\mathrm{ABA}, \mathrm{CO}_{2}$, light and water potential, but fail to close fully. J. Expt. Bot. 258:99-107.

Schoch, P.G., C. Zinsou, and M. Sibi. 1980. Dependence of the stomatal index on environmental factors during stomatal differentiation in leaves of Vigna sinensis L. J. Expt. Bot. 31:1211-1216.

Sciutti, R. and S. Morini. 1995. Water loss and photosynthesis of plum plantlets is influenced by relative humidity during rooting in vitro. J. Hort. Sci. 70:221-228.

Short, K.C., L. Price, and A.V. Roberts. 1981. Micro propagation of roses. In: J. Harkness (ed.). The rose annual, The Royal Natl. Rose Soc., London.

Slootweg, G. and U. van Meeteren. 1991. Transpiration and stomatal conductance of roses cv. Sonia grown with supplemental lighting. Acta Hort. 298:119-125.

Smith, M.A.L., J.P. Palta, and B.H. McCown. 1986. Comparative anatomy and physiology of microcultured, seedling, and greenhouse-grown asian white birch. J. Amer. Soc. Hort. Sci. 111:437-442.

Sutter, E.G. and R.W. Langhans. 1982. Formation of epicuticular wax and its effect on water loss in cabbage plants regenerated from shoottip culture. Can. J. Bot. 60:2896-2902.

Torre, S. and T. Fjeld. 2001. Water loss and postharvest characteristics of cut roses grown at high or moderate relative air humidity. Scientia Hort. 89:217-226.

Torre, S., T. Fjeld, and H.R. Gislerød. 2001. Effects of air humidity and $\mathrm{K} / \mathrm{Ca}$ ratio in the nutrient supply on growth and postharvest characteristics of cut roses. Scientia Hort. 90:291-304.

van Doorn, W.G. 1997. Water relations of cut flowers. Hort. Rev. 18: $1-85$.

Wardle, K. and K.C. Short. 1983. Stomatal response of in vitro plantlets. Responses in epidermal strips of Chrysanthemum to environmental factors and growth regulators. Biochemie Physiologie Pflanzen 178: 619-624.

Willmer, C. and M. Fricker. 1996. Stomata. Chapman Hall, London.

Zieslin, N., H.C. Kohl, A.M. Kofranek, and A.H. Halevy. 1978. Changes in the water status of cut roses and its relationship to bent-neck phenomenon. J. Amer. Soc. Hort. Sci. 103:176-179.

Ziv, M., A. Scwartz, and D. Fleminger. 1987. Malfunctioning stomata in vitreous leaves of carnation (Dianthus caryophyllus) plants propagated in vitro; implications for hardening. Plant Sci. 52:127-134. 